\title{
Aspects of Distance Education in Combination with Home Offices
}

\author{
Petr Rozehnal * and Roman Danel \\ Department of Applied Informatics, Faculty of Economics, VŠB-Technical University of Ostrava, \\ 70800 Ostrava, Czech Republic; roman.danel@vsb.cz \\ * Correspondence: petr.rozehnal@vsb.cz; Tel.: +420-597-322-320
}

check for

updates

Citation: Rozehnal, P.; Danel, R. Aspects of Distance Education in Combination with Home Offices. Information 2021, 12, 75. https:// doi.org/10.3390/info12020075

Academic Editors: Antonin Pavlicek and Petr Doucek

Received: 22 January 2021

Accepted: 6 February 2021

Published: 10 February 2021

Publisher's Note: MDPI stays neutral with regard to jurisdictional claims in published maps and institutional affiliations.

Copyright: (c) 2021 by the authors. Licensee MDPI, Basel, Switzerland. This article is an open access article distributed under the terms and conditions of the Creative Commons Attribution (CC BY) license (https:// creativecommons.org/licenses/by/ $4.0 /)$.

\begin{abstract}
This article discusses the impact of a lockdown caused by the novel coronavirus disease 2019 on the educational process at a selected faculty of a public university in the Czech Republic focused on economic education. The aim was to capture relevant aspects in the context of impacts on the management of the educational process in the organization. The unique situation brought the possibility of analyzing the flexibility of the organization, its ability to adapt. A questionnaire survey was conducted among academics. We found out how they coped with this situation, their technical equipment, support from the faculty, and whether they encountered any problems. The goal of the article was not to bring an exact evaluation of selected questions, but to show the state of the actual situation, to point out possible problems of users, and to link these things with the approach to the management of the organization. Based on the analysis, we bring suggestions and recommendations for improving the process of transition to online learning as well as distance education management and recommendation to support teaching, regardless of the teacher's workplace. The basic areas and activities that need to be managed were also identified.
\end{abstract}

Keywords: on-line teaching; Teams; home office; management of the educational process

\section{Introduction}

In 2020, the spread of novel coronavirus disease 2019 infection considerably changed the functioning of the whole society across countries around the world within a few weeks. In most countries, quarantine was subsequently imposed, making it necessary to work in the form of a home office.

This paper deals with some aspects of home offices at higher education institutions during quarantine. Although universities have experience with distance learning, the transition of all lectures to an online form was a completely new situation. Universities had no experience with such a range of distance education.

Retrospectively, we had the opportunity to observe a situation that was historically unique for a period of about one year. It was out of the ordinary, and unpredictable. In the field of education, two areas were addressed, previously implemented, but on a completely different scale: distance learning, an element already established, but to a completely different extent; and the home office mode of work, again previously used, but implemented in principle differently.

In the spring, after several weeks of distance, online teaching, we conducted a survey at a selected faculty focused on humanities education. The faculty is a part of a public university in the Czech Republic. The research was conducted among academics and focused on the ability to carry out the online learning process without the possibility of being present at the faculty. It is important to mention that this regime was switched over in an extremely short period, without the possibility of preparation, and that the online form of education was not implemented at the faculty with regard to accredited forms of education. The pedagogical process has undergone a transformation into a digital form. At the micro level, the pillars of digital transformation according to reference [1] were documented. 
Aspects that made the situation unique in terms of these aspects are as follows:

1. The scope, which covered all academics, students and fields of study;

2. The distance form was implemented exclusively, i.e., verification and evaluation of students, processing the study agenda, etc.;

3. Change of the transition to the distance form was in the order of days;

4. The home office regime applied to all academics (also to other staff providing educational support).

The aim of this paper was to analyze the situation and, if necessary, define long-term process recommendations that will support work in the home office. The motivation for these activities is the goal of the faculty management to provide long-term full-fledged education in the distance regime based on IT (information technologies). The aim is to offer education in various modes according to the current situation and preferences. Real-time teaching should be primary. Therefore, it is important to distinguish terms describing the method of teaching. The term "online" mainly expresses the use of the internet and IT for teaching. Real-time expresses the learning process in real time. In combination with teaching materials, it is thus possible to define several basic modes of teaching, which make demands on pedagogical and technical support. For example, the lecture can be provided in real-time as a video stream with the possibility of student interactivity (later it can be available as a video), but also as a pre-recorded video published for viewing.

Types of learning:

- Online, real time. For example, streaming via MS Teams, Zoom, etc.;

- Online, with time independent study materials. For example, pre-recorded video;

- Hybrid, at the same time face to face and online, real time or online, time free;

- Online, real time for students with special needs.

In addition, the management of the faculty is aware of the need to remotely provide not only pedagogical activities, but also activities related to the organization of studies. The experience of academics is usable for these processes.

At the faculty, the full-time teaching regime has always been supplemented by support for elements of e-learning. Even before the emergency, appropriate technologies for the distance form of teaching were available. However, their use was not essential. In particular, no emphasis was placed on teaching from outside the faculty (university).

The faculty uses LMS (Learning Management System) Moodle to support teaching (no matter what form of study), lecture recording system with subsequent export to video and placement in university systems (video, audio, and presentation), and Office365 for remote work; selected software is available via the internet (remote desktop connection). It can be stated that the university had technologies with which it was possible to implement the teaching process online immediately. Of course, the reality of switching to home office mode was not easy.

The consequences of this change were mainly reflected in:

- The necessity to have adequate technical and software equipment;

- The need for a quality internet connection;

- The need to have the same data available at home as in the university environment;

- Sufficient knowledge to use technologies that support home office work and teaching process applications.

The faculty management strategy in an emergency was simple. Primarily, the goal was to replace full-time teaching with real time online teaching as much as possible. Secondarily, it was to ensure supplementation of the study materials with elements typical for distance education and replace personal form of communication with electronic equivalents.

The primary goal was technically based on Office 365 applications, especially Microsoft Teams [2], which are available to all university users (academics and students). Real-time teaching recordings were also made. In addition to traditional teaching materials, offline videos were also deployed, which could be produced individually only with the assistance of a computer, i.e., screen capture software. 
For a longer period, this initial strategy was to:

1. Take into account the experience of teachers in improving education in general (pedagogical factors);

2. Remove negative factors limiting education (technical-organizational factors, e.g., replacement of writing on classic whiteboards);

3. Introduce long-term measures to support online distance learning at all levels of management and in all relevant areas.

\section{Literature Review and Methods}

\subsection{Recent Studies Analysis}

The topic of distance education with the support of information technologies has been the focus of attention in the last year. Many studies related to a selected aspect of education have been published. Great attention is paid to the field of pedagogy and psychology of teachers and students, the main actors in the educational process.

One article [3] reported one of the first investigations conducted in Italy, with the aim to capture teachers' perceptions about the capability to react to the lockdown and the recourse to on-line learning. The study shows that the learning ecosystems reacted promptly to assure didactic continuity. Another finding is the perception of the working load increase generated by online learning, restructure activities and content and also by learning new tools and strategies. Another study [4] revealed perceptions of the teachers, administrators and academics who had to continue distance education. A working group of 65 teachers was analyzed. The study found difficulties in students' internet access and the consequent lack of infrastructure and classroom management.

One report identified the main problems faced by teachers and students from different countries in Latin America, when using e-learning platforms in a lockdown scenario, reporting the importance to include aspects related with emotions and awareness [5].

In reference [6], the authors conducted a worldwide survey based on teachers' perception to explore the experiences of higher education faculty who converted classes to a distance learning format. Respondents said that they learned the need for adaptability and good planning, emphasizing doing what it takes to serve their students. The recommendation based on findings included the need for better online distance learning instructional design training as part of long-term professional development. Higher education institutions should provide theory-based training and mentoring to faculties concerning distance learning and instructional design, not just about the hardware and software. The study revealed that many students disengaged from online classes because they missed having face-to-face conversation. Particularly for undergraduate students, their personal growth and development experiences cannot easily be replicated in the online delivery of classes.

Reference [7] surveyed the undergraduate and postgraduate students to find their perceptions about distance and online education in Portugal. According to the study, students felt that the need for face-to-face classes was of great importance for practical and laboratory classes. The paper emphasizes that for future research, it is important to understand the consequences of this type of teaching on the success of students. In reference [8], student behavior was analyzed to understand why they did not turn on their camera during classes. The reason was not only technological, but other aspects such as social norms also played a role. The aim was to understand students and engage them in active learning.

The organization of distance education with IT support in the context of the institution is given secondary attention. Barret states the need for a long-term and holistic approach [9]. Lacuzzi, Fedele and Garlatti [10] emphasize the need for strategies to navigate such crises. They investigate how schools reacted to the crisis and focuses on their knowledge management strategies. A school's capital consists of general knowledge, school policies and processes, and administrative procedures [11].

According to Huang et al., it is necessary to prepare resources for teaching, both technological and pedagogical [12], ensuring that resources are based on the organization's 
ability to support their availability. This applies to both material provision (hardware and software equipment at the individual level of the student and teachers) and organizational (adjustment of the organization's processes supporting teaching, ensuring the environment, etc.).

A different study aimed to reveal insight into educational design of Massive Open Online Courses (MOOC), in particular on their educational ability [13]. The analysis indicated scalable best practices on various complexity levels and across different learning activities for online education in general.

A systematic review examining 619 research articles on online learning published in twelve journals in the last decades provided a taxonomy for categorizing learner characteristics [14].

Learning time and learning motivation using questionnaires was measured in reference [15]. A stepwise regression analysis revealed that studying at the optimal time of the day and studying regularly are relevant predictors of academic success. To optimize learning efficiency and minimize teaching bias, it is paramount to investigate variables predicting academic success. Personality traits, cognitive abilities and learning behavior are crucial determinants for academic success in blended learning.

\subsection{Methods Used}

A basic tool used in the research was the survey that was conducted in the faculty's academic staff (academics and Ph.D. students). We used Forms in Office365 due to the online availability for the target group as a technical means for the implementation of the questionnaire research.

Respondents were addressed by targeted email with a link to the questionnaire containing 12 questions, and 230 respondents were addressed in total. The questionnaire was returned by $26.5 \%$. In order to assess the return rate, it is necessary to take into account that about $25 \%$ of academics are internal Ph.D. students and colleagues from abroad. These academics are not primarily responsible for course management and their role in teaching is secondary.

The survey did not take into account gender issues, the age of respondents, belonging to a professional specialization, and other issues related to the respondent's specification. These questions were not relevant to the application of the results and the aim of the survey. The aim of the survey was to analyze the factors related to the long-term ability of the faculty to use resources efficiently, to ensure flexibility and quality strategic management at the level of the institution (not at the level of the individual).

The survey sought answers to the following research areas:

- RA1. What is the technical equipment necessary in the home office? Do academics have the hardware needed for real time online learning?

- RA2. What is the availability of software equipment for academics and students?

- RA3. What is the level of access to work data in home offices? Do academics have equal access to working data in home office compared with the normal mode of operation when they are present in the workplace?

- RA4. What is the quality of the internet connection? Does the quality of the internet connection limit real time teaching?

- RA5. To what extent has the transition to full-fledged online education been implemented (according to the teaching elements applied in online teaching process)?

- RA6. Specification of the most common problems, any further notes, and ideas.

\section{Survey Analysis Conducted in the Spring and Its Evaluation}

\subsection{Quantitative Analysis}

Although the questions were mainly open (or at least with the possibility to write a comment) it was possible to perform quantitative analysis of results. The reason for this concept of open questions was the possibility of respondents to express information freely without restricting the preference. In retrospect, we evaluate it positively. Respondents, 
for example, mentioned software that would be difficult to predict when preparing a questionnaire. All questions in the questionnaire were focused on the six areas mentioned above. The sequence of questions was intentional. Several questions followed logically, in order to address the research area from several perspectives. In the following section, we present the basic quantitative findings.

\subsubsection{RA1. Technical Equipment}

In general, the hardware equipment was adequate. The advantage was a large proportion of portable devices. There were indications that there was a lack of equipment to support a specific pedagogical process (e.g., electronic boards). With the global transition to real time mode, it will also be necessary to provide hardware for this form, such as a camera and a microphone.

- $10 \%$ of respondents reported insufficient technical equipment (5\% hardware quality and $5 \%$ missing hardware, equipment specially designed for teaching);

- $\quad 3 \%$ of respondents reported a scanner as missing hardware;

- $6 \%$ of respondents mentioned a missing printer (needing to print selected materials with regard to their study, preference to work with the printed version).

\subsubsection{RA2. Software Equipment}

In the field of software, it was appropriate to distinguish two levels. Firstly, the infrastructure equipment. There are platforms for document sharing and teaching organization-LMS. There are also platforms for real time communication and teaching creating virtual learning environment with official university support (MS Teams and BigBlueButton in LMS Moodle). Secondly, there is the availability of software for individual courses, where it is necessary to ensure accessibility for both teachers and students.

- $5 \%$ of respondents said that they lacked certain software (limited-use, licensed software);

- A fundamental problem that was diagnosed on the basis of a questionnaire survey was the answer to the question "Do you know about the possibility of running some programs in the form of remote access?". A total of $29 \%$ of respondents said they did not know about this option, and $14 \%$ of respondents knew about it but could not use it. Again, this situation is caused by a lack of information about the possibilities and features that the IT infrastructure of the faculty offers.

\subsubsection{RA3. Data Availability}

The survey did not identify any problems in the availability of data to ensure work continuity. The basic variants for storing data are as follows: locally on the device, network disk mapped in the university environment, cloud storage, and portable storage of individual users. Accessing data stored on a local device is trouble-free at home as well as with portable devices. Cloud data service is available from anywhere. VPN access is required to access the faculty network drive.

- The results showed that only $11 \%$ of respondents stored data on a desktop computer to which they did not have access from home. At the same time, these users stored data on portable devices. Therefore, data availability problems were not identified;

- $55 \%$ of academics had a portable computer on which they stored data and had access to. This hardware was also equipped for audiovisual needs;

- $\quad 3 \%$ of respondents reported a confusing answer when they reported a different location where they stored data and other storage to which they had access. However, they did not report a problem with data access.

The data storage methods mentioned above were an advantage at a critical time. In the long-term period, however, they contain a hidden threat of insufficient data backup. Only for university network drives and cloud services are backups made. 


\subsubsection{RA4. Internet Quality}

Respondents assessed the quality of the internet connection according to their subjective perception. Most $(80 \%)$ respondents assessed their Internet quality as sufficient and trouble-free.

\subsubsection{RA5. The Scope of the Transition to Full-fledged Distance Online Education.}

There were three main variants of education according to the use of didactic elements.

- $\quad 47.5 \%$ of respondents used LMS and traditional materials (presentation, pdf, etc.) only with added elements such as material links, comments, and individual tasks;

- $12 \%$ of respondents used LMS, traditional materials and video recordings of lectures-partial replacement of full-time teaching;

- $\quad 40.5 \%$ of respondents used LMS, traditional materials, and real time video lectures and communication-maximum possible substitution of full-time education with the help of IT tools.

A total of $31 \%$ of teachers used different communication tools instead or together with recommended tool by university: $18 \%$ used Skype, and other applications were represented with minimum shares (for example, WhatsApp, Facebook, Zoom). In the current situation, it is difficult to assess this result. In a positive sense, this is an active approach, probably driven by efforts to maintain contact with students. In the negative sense, this implies the creation of non-standard communication channels, where it is difficult to maintain a uniform environment and way of communication.

\subsubsection{RA6. Discussion—Problems, Suggestions and Comments.}

The survey also included a completely open question. Respondents could state anything (problems, suggestions, comments, etc.):

- $15 \%$ of respondents reported their requirements for better support, e.g., information, instructions, documentation;

- $8 \%$ of respondents stated a lack of information as a problem, although this information was available (intranet, information emails, and other standard communication channels);

- $43 \%$ of respondents did not use the opportunity to write a comment, problem, or suggestion.

The other answers in this open question can be summarized in the following issues as follows:

- The problem is the lack or inadequate forms of support, e.g., documentation, tutorials, manuals, etc. The documentation is divided and available in several places and in different formats (texts, videos, pages), which complicates the search;

- Absence of coordination and unification of the teaching process;

- Online learning cannot fully represent the direct contact between students and teachers. Some courses require practical demonstrations that are difficult to implement online, and interaction with students is also important. Non-verbal communication is often reduced in online education; for example, when a teacher does not see how students respond to a lecture topic and how they understand it. Additionally, the interaction with students in online learning is more complicated-some students tend not to ask and attend only as described in reference [16], dealing with teaching using a teleconferencing system.

\section{Discussion and Practical Recommendations}

\subsection{Further Experience Associated with Online Teaching in the Winter Semester 2020/2021}

During the winter semester of the academic year 2020/2021, the situation with online distance education occurred again. It is thus possible to compare the two periods. In contrast to the spring lockdown, the transition to online teaching was organized and proceeded smoothly. The teaching environment was ready and well-known. Additionally, 
the provision of technology was mostly problem-free. In the analysis of problems, we obtained more detail, dealing with issues that were less significant in the spring or with completely new aspects.

During the semester, we identified the following problems related to online teaching:

- Awareness of the current situation and study instructions remained a key issue. This is especially true for first-year students, for whom the university environment and way of studying was new;

- For many students, distance learning has become "common" and they underestimated the situation. Some students joined classes outside the home, and interaction with them was severely limited; some students registered for teaching from mobile phones, which then reduces the quality of teaching, especially in courses where students have to work with software tools, etc.;

- It is possible to state there is a general reluctance for voice communication and a preference for the written form -in real time chat applications. It transpires that students who have to answer a question in the virtual environment of MS Teams do not use a microphone, but answer in a chat. If the teacher has a PowerPoint presentation, for example, he does not see the chat in the MS Teams environment. In this case, he must end the presentation, enter the chat, and then continue the presentation. The solution is two monitors, where one displays the study environment (such as MS Teams), and the other is used to present the curriculum;

- In the case of the teacher cooperating with another university (e.g., as a visiting professor), if both institutions use the same means of communication-for example, Teams-parallel work can be complicated. MS Teams does not allow users to be logged in under two accounts at the same time, so in this situation it is necessary to constantly $\log$ in/out and the teacher is not "online" for the other institution. Working in Teams may be complicated in terms of a different software settings in both institutions;

- Interaction and involvement of students is different from in-contact teaching-in most groups, there are several students who respond and have questions, others are usually passive;

- Some students do not have computers with the latest hardware at home and are therefore forced to use older versions of some software resources, even though they have school licenses for new versions available (for example, Office, due to the fact that newer versions cannot run on old hardware). This problem would not arise at all in the case of contact teaching in computer classrooms at school.

Based on the analysis of data obtained from the survey and the experience resulting from the academic environment, recommendations for the transition to a distance (online) form of education will be further formulated.

\subsection{A Comprehensive Approach to Solutions}

The recommendations are based on the classic three-level management level model $[17,18]$. In the future, overall preparedness will be key for the effective management of educational institutions in similar situations. It must not be just a short-term, technical solution, but a long-term ability to react. The situation in the future may be different (reasons, speed of change, etc.), but the ability to be flexible must be maintained.

It is worth noting that the recommendations that would define the hardware equipment (including technical specifications, network throughput requirements and other details) and software configuration (in terms of its implementation and configuration) are outside the scope of the article. The aim was to point out the organizational and procedural context of the use (in principle) of existing resources, promoting their flexibility, and improving management.

The concept of the proposed recommendations is described in Figure 1. Technically, it is a matter of providing the necessary resources and their appropriate management and development. The content of all levels is interlinked. This seemingly simple principle is extremely important. In the survey results, this was shown: the non-uniform interface of 
communication between students and teachers with the absence of management (and thus a unified approach) led to the use of many different communication/teaching tools.

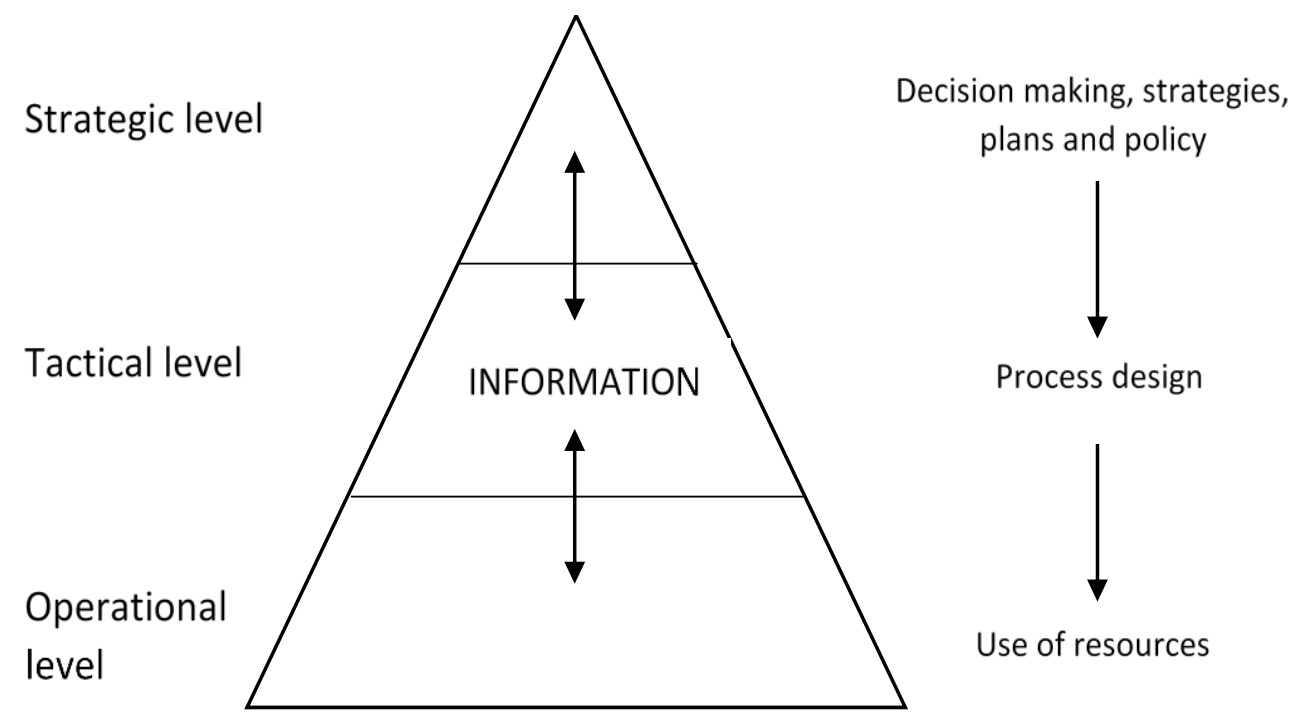

Figure 1. A three-level management model, developed by the authors.

The Strategic level is focused on long term, strategical issues. We can mention IT strategy and educational strategy in particular. These two documents are key for process organization and present plans for future.

Significant parts of the policy, based on this level of management, are to have a vision in which the organization is flexible and to have a virtual environment that provides the processes necessary for education process.

The following areas can be supported at this level of management:

1. Pressure to digitize processes related to the teaching process (study agenda, electronic documentation, etc.);

2. Software to support the study agenda and teaching (e.g., LMS, workflow, communication);

3. IT equipment on the part of end users (orientation to portable devices);

4. Pedagogical readiness of courses (provision of teaching materials, know-how of preparation of teaching aids);

5. Readiness of software used in teaching (for example, some students use Apple devices and may have trouble using some standard programs);

6. Equipment of the organization for creating materials and support for their preparation (hardware, software, manuals, staffing);

7. The overall concept of study organization, including the implementation of student testing, credits, and exams.

The tactical level is responsible for the implementation of plans and objectives defined at a higher level. For this level, the primary task is to define, implement and manage processes.

In the discussed area, these are the processes:

1. Help Desk function for managing specific requirements for non-standard periods (technical problems with online teaching, ignorance of procedures);

2. Information management (within existing systems and communication channels);

3. Define and manage study affairs processes;

4. Define and manage educational processes;

5. Establish the process of supporting the creation of teaching materials.

Operational level is a level in which short-term operational issues related to day-to-day activities are realized. 
The readiness to avoid ad hoc solutions is key for the implementation of proper activities, which will not lead to shortcomings and difficulties. Elements of the teaching process are implemented; many are specific to the distance form (e.g., ensuring verification of students' identity during online testing, motivating students to participate in classes actively and not just by formally registering for the meeting).

In the following chapter, we describe the areas we have identified, and which may be a challenge for a solution.

\subsection{Related Areas to Solve}

In addition to these levels of management, three areas have been identified that are of particular significance in the educational institution: areas of education (pedagogy), information and management. Outside the educational environment, the area of education will not be applied, while the area of information will be important in all types of organizations.

\subsubsection{Area of Education}

Several characteristic teaching scenarios have been identified. The basic aspects that make up these scenarios include:

- Location from which the teaching is realized-from a university or faculty versus from home (home office);

- Support required for the implementation of teaching; with or without the support of specialists;

- Time aspect. Is this a teaching in real time or time-independent teaching? Generally, the preparation of materials whose use is time-independent;

- Students. Is it necessary to take into account students with special needs? Where are the students from? Different geographic locations may occur in different time zones;

- Software needed for education. In addition to the infrastructure platform for teaching (LMS, online communication), the availability of software related to teaching (graphics, statistics, modeling software, etc.) should also be considered.

The combination of the above factors creates a number of situations that must be solved organizationally, technically, and supported by appropriate teaching materials. For example, in online, real time education based on the presentation, all students are in the distance form of education and the teacher is at the faculty versus the same situation with one different. Students are partly at the faculty and partly in the distance form. The following section considers the situation in which the education requires software that is not a common part of a computer installation.

\subsubsection{Area of Information}

All levels of management should be part of one information area. We understand the information area not only by sharing information in the form of directives, orders, and decrees, which are of a legislative nature. It is also about transferring requests, sharing manuals, publishing instructions, guidelines, training, questions, and a suitable way of communication, which will replace personal communication. The traditional communication channels that ensure the sharing of information have been disrupted by the coronavirus situation. There is a need to replace them.

Based on the experience in emergency and the evaluation of our survey, the following minimum, basic characteristics of information can be derived:

\section{Availability; \\ 2. Understandability; \\ 3. Currency.}

For the long-term creation of a flexible environment, it is appropriate to assess the quality of information more comprehensively, for example according to the COBIT framework, which defined quality criteria in version 5 [19]. This model is also suitable for describing the three aspects that we need to achieve in relation to information. It is an internal quality of 
information (in the original terminology of COBIT: intrinsic), it has good usability (COBIT: contextual) and proper sharing of information (COBIT: security/accessibility).

The broader concept of the information area, as mentioned above, includes suitable means of communication and a suitable form of information transmission. For example, personal communication is realized online in the form of chat, calling, image sharing, etc. In many cases, it is possible to prepare for information needs. It is mainly about sharing know-how in the form of training, manuals, instructions. A long-term, conceptual, and comprehensive approach is essential for implementation.

\subsubsection{Area of Management}

The two areas mentioned above and other factors influencing the educational process are connected by the area of management. The ability to manage available resources, combine them effectively, and use them is one of the tasks of management. Management structures also co-create the organization's policy, rules, and adjust processes in the organization. We have presented a general approach to the management model in Figure 1.

\subsection{Limitations of Work}

This article focused on the field of humanities studies, which does not require laboratories, clinical and practical teaching, or practice. As stated above, the aim was not to define specific system configurations, their parameters or implementation details.

Although the conclusions of the article are basically general, it is true that the initial situation and focus of the survey arose from the goals and situation of a particular entity.

\subsection{Summary}

Integration into the policy of the organization is a prerequisite for long-term assurance of the education during emergency measures and quarantine, primarily in the areas of human resources management, education, and IT management. Once again, the wellknown fact that people and their abilities are a key resource has been confirmed. Only if there is an alignment between all the resources necessary to carry out the process can be the desired effects achieved. For the above-mentioned flexibility, it is essential to manage process management, because these are the bearers of the dynamics of the organization. This confirms the direction in which the latest IT frameworks work [20,21]. It is an element of "capability" as an overall expression of the ability to act.

Results and ideas of the article can be used by the academic community in the field of team cooperation on projects, remote consultations and consultancy, and to conduct lectures and workshops led by practitioners, external experts or academics from other universities without the need for their physical presence. The results can also be valuable for other types of institutions as well as for commercial companies-possibilities of cooperation on the one hand and the need to be prepared for remote communication and cooperation states [22]. The above-mentioned need for description of the process and documentation is necessary.

\section{Conclusions}

The article describes the results of a survey in terms of the ability to implement the teaching process in an online form in home office mode and was conducted among academics carried out in spring 2020. Subsequently, aspects important for the flexibility of the educational institution in crisis periods are presented when it is necessary to implement the teaching process via the internet. The article also includes a short description of the situation from autumn 2020. It is thus possible to distinguish the situation at a time when it was no longer sudden, and it was possible to prepare further details.

The survey was conducted under circumstances which have not been experienced before. Therefore, its results are valuable as an example of knowledge of the key product for online communication and cooperation supported at the university.

The basic quantitative findings of the survey include: 
- Total technical equipment is sufficient. The advantage is equipping staff and students with portable computers. There were indications that there was a lack of equipment to support a specific pedagogical process (e.g., boards);

- Overall software availability is sufficient. Applications for creating a virtual learning environment are available;

- The problem is the lack of or inadequate form of support, e.g., documentation, tutorials, manuals, etc.

- Strong tendency of academics to use other solutions from recommended ones (especially in the area of communication with students).

The emergency situation has clearly shown that the ability to predict and overall preparedness is key to flexibility. The following example demonstrates this. MS Teams software was available at the analyzed faculty even before the emergency (similarly to many organizations where Office 365 was implemented); however, its knowledge was almost nil. At a critical moment, adequate training of employees was sufficient for transition to this communication platform. The speed of this change would not be possible if the software was not available at all and was not connected to other systems.

The idea of flexibility must be integrated into the organization's policy and strategy. This is a prerequisite for ensuring long-term preparedness for similar crisis situations. It is necessary to ensure not only the connection to the implemented processes as elements of the dynamics of the organization, but also their permanent updating. Continuous improvement of processes will ensure their timeliness and improve responsiveness.

Readers should be cautious about over-generalizing the results due to the short time period for data collection. Converting a face-to-face course to online requires considerable modification of lesson plans, schedules and learning activities. Long-term professional development of lecturers is also important, as is the entire background of the organization.

Future research should address the impact of online teaching on students' exam results and, in the long-term, on their post-school knowledge. The aim of the research should also be an organization's response in the context of last year and the long-term effect on the behavior of educational institutions.

Author Contributions: Conceptualization, P.R. and R.D.; formal analysis, R.D.; methodology, P.R. All authors have read and agreed to the published version of the manuscript.

Funding: This research received no external funding.

Data Availability Statement: Data are available from authors on request.

Conflicts of Interest: The authors declare no conflict of interest.

\section{References}

1. Doucek, P.; Fisher, J.; Novotný, O. Digital economy. In Proceedings of the 25th Interdisciplinary Information and Management Talks-IDIMT, Poděbrady, Czech Republic, 6-8 September 2017; pp. 33-40.

2. Duffy, J. Microsoft Teams Review. Available online: https://www.pcmag.com/reviews/microsoft-teams (accessed on 18 August 2020).

3. Giovannella, C.; Passarelli, M. The effects of the Covid-19 pandemic seen through the lens of the Italian university teachers and the comparison with school teachers' perspective. Interact. Des. Archit. J. 2020, 120-136.

4. Sari, T.; Nayir, F. Challenges in distance education during the (Covid-19) pandemic period. Qual. Res. Educ. 2020, 9, 328-360. [CrossRef]

5. Collazos, C.A.; Fardoun, H.; AlSekait, D.; Pereira, C.S.; Moreira, F. Designing online platforms supporting emotions and awareness. Electronics 2021, 10, 251. [CrossRef]

6. Marek, M.W.; Chew, C.S.; Wu, W.V. Teacher experiences inf converting classes to distance learning in the COVID-19 pandemic. Int. J. Distance Educ. Technol. 2021, 19, 89-109. [CrossRef]

7. Goncalves, S.P.; Sousa, M.J.; Pereira, F.S. Distance learning perceptions from higher education students-the case of Portugal. Educ. Sci. 2020, 10, 374. [CrossRef]

8. Castelli, F.R.; Sarvary, M.A. Why students do not turn their video cameras during online classes and an equitable and inclusive plan to encourage them to do so. Ecol. Evol. 2021. [CrossRef]

9. Barrett, P.; Treves, A.; Shmis, T.; Ambasz, D.; Ustinova, M. The Impact of School Infrastructure on Learning; The World Bank Group: Washington, DC, USA, 2019. [CrossRef] 
10. Lacuzzi, S.; Fedele, P.; Garlatti, A. Beyond coronavirus: The role for knowledge management in schools' responses to crisis. Konwledge Manag. Res. Pract. 2020. [CrossRef]

11. Cheng, E.K. Knowledge management strategies for capitalizing on school knowledge. VINE J. Inf. Knowl. Manag. Syst. 2017, 47, 94-109.

12. Huang, R.H.; Liu, D.J.; Tlili, A.; Yang, J.F.; Wang, H.H.; Zhang, M.; Zhuang, R.; Berrad, K.; Burgos, D.; Chen, N.S.; et al. Handbook on Facilitating Flexible Learning during Educational Disruption: The Chinese Experience in Maintaining Undisrupted Learning COVID-19 Outbreak; Smart Learning Institute of Beijing Normal University: Beijing, China, 2020.

13. Kasch, J.; Van Rosmalden, P.; Kalz, M. Educational scalability in MOOCs: Analysing instructional designs to find best practices. Comput. Educ. 2021, 161, 104054.

14. Martin, F.; Sun, T.; Westine, C.D. A systematic review of research on online teaching and learning from 2009 to 2018 . Comput. Educ. 2020, 159. [CrossRef]

15. Jost, N.S.; Jossen, S.L.; Rothen, N.; Martarelli, C. The advantage of distributed practice in a blended learning setting. Educ. Inf. Technol. 2021. [CrossRef] [PubMed]

16. Danel, R.; Řepka, M.; Valíček, J.; Kušnerová, M.; Harničárová, M. Education and research in informatics and automation at Faculty of Mining and Geology. In Proceedings of the CSIT 2018-Computer Science and Information Technologies, Plenary Session, Amman, Jordan, 11-12 July 2018; Springer Book: Lvov, Ukraine, 2018; pp. XV-XXI.

17. Dohnal, J.; Pour, J. Architektury informačních systémů: V průmyslových a obchodních podnicích. In Information Systems Architectures: In Industrial and Commercial Enterprises; Ekopress: Praha, Czech Republic, 1997.

18. Laudon, K.C.; Laudon, J.P. Management Information Systems: Managing the Digital Firm, 12th ed.; Pearson Education India: Harlow, UK, 2012.

19. ISACA. COBIT ${ }^{\circledR}$ 5: Enabling Information; ISACA: Rolling Meadows, IL, USA, 2013.

20. ISACA. COBIT ${ }^{\circledR} 2019$ Framework: Introduction and methodology. ISACA: Schaumburg, IL, USA, 2018.

21. The Open Group. TOGAF 9.2. Available online: https://pubs.opengroup.org/architecture/togaf9-doc/arch/ (accessed on 12 April 2020).

22. Ministr, J.; Pitner, T. Towards an ecosystem for academic-industrial cooperation. In Proceedings of the 22nd Interdisciplinary Information and Management Talks-IDIMT 2014 (Networking Societies-Cooperation and Conflict), Linz, Austria, 10-14 September 2014; Trauner Verlag Universitat: Poděbrady Czech Republic, 2014; pp. 71-78. 